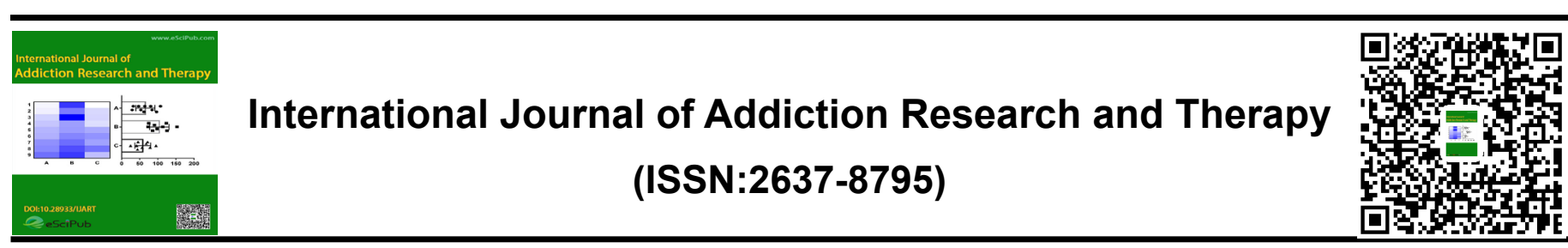

\title{
Cultural Competence, Race, and Ethnicity in Community Based Recovery Treatment Programs
}

\section{Pascal Scoles, DSW,LCSW}

Professor, Behavioral Health and Human Services and Director, Office of Collegiate Recovery, Community College of Philadelphia, PA.

\footnotetext{
ABSTRACT

Cultural competence is more than speaking the language or recognizing the cultural icons of a given group of individuals. Treat- Pascal Scoles, DSW,LCSW ing the individual is treating their culture. A culturally competent Professor, Behavioral Health and treatment professional must acknowledge an individual's cultural Human Services and Director, Ofstrengths, values, and experiences while encouraging behav- fice of Collegiate Recovery, Comioral and attitudinal change. A significant variable in the change munity College of Philadelphia, PA. process is the relationship between racial or ethnic matching of clients and counselors. Successful treatment reveals a group of cultural dynamics on how this therapeutic alliance might affect treatment outcomes. To meet these complex cultural challenges, the movement towards a pluralistic cultural framework of helping with its bilingual and bicultural sensitivity appears to be a significant variable to engage the community and the individual in the healing process. Environmental exposures, such as pollution, high-crime areas, and lack of parks or playgrounds, social services, such as transportation, housing, and childcare, mental health care, significantly impact on lifestyle choices. Building strong, grassroots recovery community organizations (RCOs) and linking RCOs into a national movement to develop recovery leaders, offer many opportunities for the recovery community. It helps people in recovery, family members, friends, and allies to How to cite this article:

Pascal Scoles. Cultural Competence, Race, and Ethnicity in Community Based Recovery Treatment Programs.International Journal of Addiction Research and Therapy, 2020, 3:22 express their collective individual and neighborhood voices on issues of common concern by providing a forum for recovery-focused community services that support individual growth.
} 
Being culturally competent in the delivery of effective treatment services means more than speaking the language and recognizing the cultural icons of people. Culturally effective and relevant care professionals must understand and respect a person's values and beliefs. This cultural proficiency is accomplished through the efforts of a counseling staff trained to understand and appreciate the attitudes, ideas, and behaviors of culturally, ethnically, and racially different individuals ${ }^{1}$.

We know that culture permeates all life domains. Many therapists believe that when you treat the individual, you address their culture ${ }^{2}$. Also, anxiety and stress is heightened in the lives of those living in a sociocultural setting other than the one they come from ${ }^{3}$. One way to manage this stress is through the acquisition of knowledge about different cultures. Cultural experience enhances the understanding of diverse worldviews, reduces anxiety and provides insight into the optimum approach to problem-solving strategies ${ }^{4}$. Cultural knowledge and sensitivity is a set of academic and interpersonal skills that allow individuals to increase their understanding and appreciation not only cultural differences but also similarities within, among, and between groups ${ }^{5}$. In a treatment setting, cultural sensitivity must evolve into cultural competence, a fundamental ingredient in understanding how members of different cultural groups define health, illness, and health care ${ }^{6}$. A culturally competent treatment professional acknowledges an individual's strengths, values, and experiences while encouraging behavioral and attitudinal change.

Researchers have described cultural competence as a clinical continuum in which the clinician increases his or her understanding and effectiveness with different racial and ethnic groups ${ }^{7}$. The clinical pathway to cultural competence moves through four phases:

- Cultural destructiveness, where individuals regard other cultures as inferior to their dominant culture, to more positive attitudes and higher levels of skills described below.
- Cultural sensitivity are individuals who have limited cultural knowledge and may still think in terms of stereotypes.

- Cultural competence includes an ability to "examine and understand nuances" and exercise cultural empathy, thereby sensitizes the counselor to the client's perspective.

- Cultural proficiency is the highest level of regenerative capacity. The culturally proficient counselor works to advance the field through leadership, research, and outreach ${ }^{7}$.

It is important to note that clients, not counselors, define what is culturally relevant to them. It is helpful to remember that all human beings represent multiple cultures. Clients are not merely African American, Caucasian, Asian, etc. A relatively large group of social scientists believe that ethnic identity is a significant cultural variable that impacts a person's s concept of belonging with other subgroups. This subgroup defines the individual's relationship to the dominant culture. A person's shared cultural influences can affect an individual's willingness to seek help concerning a behavioral health challenge ${ }^{8}$.

To further complicate the behavioral health challenge, a person's cultural perspective impacts on how an individual may describe his behavioral health challenges to a professional worker ${ }^{9}$. Although there is an historical thought that only people who experience trauma and addiction are best suited to help similar people. It should be noted that what is equally important is that the counselor possess and or be receptive to similar feelings and struggles. In many ways, our differences are as significant as our similarities. Although our differences can affect the evaluation process, there is no clear evidence that cultural or religious differences necessarily impairs outcome ${ }^{10}$. We know that Insensitive Euro-Americans (Whites) are just as problematic as insensitive African Americans, Asian Americans, Latinos, or Native Americans.

Cory (2017) in his discussion of cultural insensitivity in clinical practice established some practical guidelines for working effectively with people 
from diverse populations:

- Learn more about your culture and how it has influenced your behavior and thoughts about others.

- Identify for yourself underlying assumptions about culture, race, ethnicity, gender, etc.

- Expand your knowledge and experience with other cultural groups.

- Learn to find your common ground with people of diverse backgrounds.

- Recognize the importance of being flexible in the application of techniques that benefit different cultures ${ }^{11}$.

Research on the relationship between racial and ethnic matching of clients with counselors in a treatment context reveals a complex dynamic on how the therapeutic alliance might affect treatment outcomes. Some individuals prefer counselors from their same racial/ethnic/cultural background; this is not always sufficient to ensure client engagement and retention ${ }^{12}$. Similarities, different sociodemographic variables, as well as, level of acculturation, also appear to affect the nature of the therapeutic relationship.

\section{Race and Culture}

Race, as a variable in counselling, is often thought to be based on genetic traits (e.g., skin color, etc.), but there are no reliable means of identifying race based on genetic information. Indeed, over $80 \%$ of human genetic diversity is found within any "racial" group. Thus, what we perceive as diverse races are much more genetically similar than they are different. Physical characteristics ascribed to a particular racial group can also appear in people who are not in that subgroup ${ }^{13}$. Although race lacks a genetic base, the concept of race is essential in discussing cultural competence. In reality, the social construct of race does describe people with shared physical characteristics. The major racial groupings designated by the U.S. Census Bureau are limiting because they are categories developed to describe identifiable populations currently within the United States. It should be noted that the U.S. Census defines Hispanics/Latinos as an ethnic group rather than a racial group (see the "What Is Ethnicity?" section later in this article). Racial identification does not always have a definite meaning in other parts of the world; racial identity as a defined group can change according to one's current environment or society ${ }^{14}$.

For example, "Whites" are often referred to collectively as Caucasians. However, technically, the term refers to a subgroup of "White people" from the Caucasus region of Eastern Europe and West Asia. Also, the names African American and Black are used synonymously at times in literature and research. Still, some recent immigrants do not consider themselves African Americans if the designation only applies to people of African descent born in the United States. The racial classification Black, however, encompasses a multitude of cultural and ethnic variations and identities (e.g., African Caribbean, African Bermudian, West African, etc.). The history and experience of African Americans have varied considerably in different parts of the United States. The experience of Black people in this country varies, even more, when the culture and history of more recent immigrants are considered. Today, African American culture embodies elements of Caribbean, Latin American, European, and African cultural groups. Brisbane 15 observed that "these cultures are so unique that other African Americans may not understand some African Americans' practices. There is no one culture to which all African Americans belong" (p. 2).

Finally, the concept of ethnicity differs from race in that groups of people can share a common racial ancestry yet have very different ethnic identities. Thus, by definition, ethnicity-unlike race-is an explicitly cultural phenomenon. It is based on a shared cultural or family heritage and shared values and beliefs rather than shared physical characteristics ${ }^{16}$.

\section{Ethnicity and Culture}

The term "ethnicity" is sometimes used interchangeably with "race," even though they are distinctions between the two. Yang ${ }^{17}$, indicates 
that ethnicity refers to the social identity and belonging that defines a group of people through common historical or family origins, beliefs, and standards of behavior (i.e., culture). For example, the White Anglo-Saxon Protestant peoples of England and Northern Europe have different cultural attributes and very different histories in the United States than the Mediterranean peoples of Southern Europe (e.g., Italians, Greeks).

Two factors should be emphasized about race, ethnicity, and culture:

1. Too many Euro-Americans (Whites) have limited experiences with minority communities, cultures, and concerns. Generally, Americans continue to go to different schools, live in non-integrated neighborhoods, attend segregated churches, and socialize in different parts of the community. Social scientists, as well as many others, believe that groups who live separately and don't know or understand each other, have difficulty trusting one another, and know very little about the social and cultural realities of individuals different from their world view. Book knowledge about culture is not the same as living with different cultures and experiencing different cultures. Too often, behavioral health counselors enter the heaping professions with no meaningful contact or exposure to other cultures.

2. The interpersonal relationship or the development of effective therapeutic relationships fosters the kind of respect, professional courtesy, and competence that helps experienced; skilled practitioners work effectively with culturally dissimilar people. Expertise in assessment and treatment requires that the counselor have sufficient breadth and depth in (1) cultural awareness and sensitivity, (2) a body of multicultural knowledge and experience, as well as, (3) a specific set of practice skills ${ }^{18}$.

In conclusion, ethnicity differs from race in that groups of people can share a common racial ancestry

yet have very different ethnic identities. Thus, by definition, ethnicity, unlike race, is an explicitly cultural phenomenon. It is based on a shared cultural or family heritage as well as shared values and beliefs rather than shared physical characteristics.

\section{Cultural Competence and Recovery}

Within a recovery and resilience-oriented setting, cultural competence is a fundamental ingredient that helps develop trust and an understanding of how members of different cultural groups define health, illness, and health care ${ }^{19}$. A culturally competent recovery/resilience" (1) understands issues of race and ethnicity, (2) acknowledges the person's cultural strengths, values, and experiences and (3) encourages behavioral and attitudinal change. White, et al. ${ }^{20}$ in his discussion of the recovery revolution, explores the definition of resilience in this way:

Resilience is the ability of individuals to remain healthy even in the presence of risk factors. It can be thought of as protective shields existing at multiple levels of the ecosystem or as relational processes across these levels that bestow varying degrees of immunity in the face of risk exposure. Definitions of resilience widely differ. Some define resilience as a protective cultural shield of traits that neutralize risk factors to yield a state of invulnerability or extreme hardiness. Others define resilience as the ability to rebound from negative influences and traumatic experiences. Some of the latter definitions use resilience and recovery interchangeably or link the two conditions.

Recovery/resilience-oriented models of care that are culturally responsive are characterized by:

- Helpers knowledge of the native languages of the people receiving service.

- Helpers sensitivity to the cultural nuances of those receiving services.

- Helpers backgrounds representative of those of the people receiving services. 
- Recovery/resilience models that reflect the cultural values and needs of the people receiving services.

- Representation of the people receiving services in decision-making and policy ${ }^{20}$.

These features alone do not constitute cultural competence, nor do they create a culturally competent system. Culturally relevant systems of care include behavioral standards for both the counseling staff and the organization. These norms must be built into the organization's mission, structure, management, personnel, program design, and recovery/resiliency protocols. To be successful, culturally competent systems need to implement cultural competence at various levels: staff attitude, practice, agency policy, and structure ${ }^{21}$.

\section{Cultural Pluralism}

History has taught us that neither the "Anglo conformity model" nor the "melting pot" ideology does justice to American racial and ethnic diversity. The concept of cultural pluralism appears to move us in the proper direction since it is based on the idea "...that the members of minority groups should be accepted as completely Americanized and assimilated without being required to disappear as distinctive groups" 22 (p.30).

Cultural pluralism implies: (1) bilingual and bicultural sensitivity, (2) a high degree of participation in education, political activity, and (3) freedom of movement in the occupational and residential business. This type of cultural pluralism supports the Jungian concept of connecting to one's collective cultural (ethnicity) unconscious. It allows one to feel a part of a broader transpersonal awareness that is not bound by racial concerns but joined together by our collective cultural pluralistic consciousness ${ }^{23}$. The inability to humanize our cultural history is a significant factor in many people's inability to empathize with cultures that are different from their heritage. The alternative to "Anglo conformity," cultural pluralism is a kind of assimilation to the American lifestyle that takes into consideration the reality that America is a "culture of ethnicity" that maintains its health by passing on a family's language and customs ${ }^{22}$ (p.451). Many non-Anglo ethnic groups see their ethnic neighborhood as

the way a group of people has chosen to express their Americanism. The community is a source of social morale and is the main link, which the individual is "plugged into" the society. The individual receives social and psychological support from family and friends in the neighborhood. Therefore, the destruction of an ethnic community does not necessarily signify the end of an alien culture and the complete adoption of American culture. It may mean, instead, the destruction of a specific way of being an American. Therefore, it is not surprising that many White ethnics, Latinos, and Blacks object to the assumption by government officials that their old ethnic neighborhoods are slums or that these groups oppose policies that further the deterioration of ethnic communities $^{22}$ (p.452).

\section{Barriers to Treatment Affecting Substance Abusers from Racial/Ethnic Groups}

Regardless of the treatment model in use, racism on an institutional or individual level is a barrier to treatment effectiveness. Institutional racism within a treatment system is evident when the program or treatment design is oblivious to the racial, cultural, or ethnic backgrounds, values, and mores of its client population and neighborhood. Latent prejudice on the part of treatment staff and language and cultural differences undermine efforts to help recipients of service (clients) achieve recovery from substance use and abuse.

Latent prejudice, coupled with a community in social and economic distress, may lead to resentment and mistrust of treatment providers who are considered "outsiders." Negative experiences with service providers who may have lacked regard, awareness, or concern for cultural differences often reinforce unfavorable attitudes and distrust. Behavioral health treatment programs may be rendered ineffective if the 
community has not been involved in its planning and implementation. To offset negative treatment planning, community treatment facilities must be sensitive to where people live, learn, work, and play. We know that: (1) poverty, (2) limited access to healthy foods, (3) a lack of safe neighborhoods, unstable housing, and (4) limited access to education are predictors of poor health outcomes. Addressing these community health concerns can improve an individual's health and advance health equity ${ }^{24 ; 25}$. It is estimated that a significant amount of individuals' health is determined by the social and environmental conditions in which an individual works, lives, and plays ${ }^{21}$. There is a growing recognition that a person's "individual health" cannot be separated from an "individual's community health." Moreover, a lack of attention to these social determinants contributes to overall "community pathology" and low therapeutic success rates $26 ; 27 ; 28$.

From a community health perspective, healing the community is a significant factor in treating the individual. Environmental exposures, such as pollution, high-crime areas, and lack of parks or playgrounds, social services, such as transportation, housing, and childcare, mental health care, also affect lifestyle choices. Therefore, a clinician's advocacy effects to intervene upon and influence these complex social, behavioral, and environmental factors would best define a community-based recovery treatment approach that integrates both the communal and individual barriers to successful healthcare ${ }^{25}$. Effective treatment planning must address the person in the environment and be sensitive to how environmental stressors such as drug infected areas, lack of access to parks and playgrounds, poor quality education, etc. on a person's psychological health ${ }^{29}$. A comprehensive health management system must embrace a holistic approach geared toward (1) the elimination of stress in the overall community; (2) be attentive toward environ-mental factors; and (3) support and provide opportunities for better housing, increased employment opportunities, and positive family activities. Without attention to these communal interventions, one will continue to live in a static environment or a neighborhood in decline, which becomes a toxic wasteland for individuals, their families, and their community ${ }^{30}$. "Where we live, work, learn, and play is as significant as our genetic code" (2). Long-term recovery from one's "disorder" is biological and psychological and communal and spiritual ${ }^{31 ; 32}$.

To effectively deal with the above challenges to recovery, the treatment community must:

1. Build strong, grassroots recovery community organizations (RCOs) and link RCOs into a national movement to develop recovery leaders, offer opportunities for the recovery community-people in recovery, family members, friends, and allies-to express their collective voice on issues of common concern, respond to community-identified recovery support needs, and provide a forum for recoveryfocused community service.

2. Advocate for meaningful representation and voice for people in recovery and their families at local, state, and federal policy levels on issues that affect their lives.

3. Assess and respond to national and regional needs related to the adequacy and quality of local treatment and recovery support services.

4. Educate the public, policymakers, and service providers about the prevalence, pathways, and styles of long-term addiction recovery.

5. Develop human and fiscal resources by expanding philanthropic and public support for addiction treatment, recovery support services, and recovery advocacy by cultivating volunteerism within local communities of recovery.

6. Create recovery community centers that make a recovery visible on Main Street and provide a setting for the delivery of non-clinical, peer-based recovery support services, supports, and activities.

7. Celebrate recovery from addiction 
through public recovery celebration events (e.g., marches, rallies, concerts) that offer living proof of the transformative power of healing.

8. Support research illuminates the pathways, processes, stages, and styles of long-term personal/family recovery ${ }^{33}$.

\section{References}

1. Substance Abuse and Mental Health Services Administration (2014) Improving Cultural Competence. Treatment Improvement Protocol (TIP) Series No. 59. HHS Publication No. (SMA) 144849. Rockville, MD: Substance Abuse and Mental Health Services Administration

2. Samuels, A. (1991). Psychopathology: Contemporary Jungian Perspective. New York: Gilford Press.

3. Scoles, P. (2020). Anger, Anxiety, and Health Determinants in the Process of Community Recovery. International Journal of Addiction Research and Therapy. Vol. 3:19.

4. Mokuau, N. (1997). Pacific Islanders. In J. Philleo, F.L. Brisbane, and L.G. Morgan, P., and Beck, J.E. The legacy and the paradox: Hidden contexts of methamphetamine use in the United States. In: Klee, H., ed. Amphetamine Misuse: International Perspectives on Current Trends (pp. 135-162). The Netherlands: Harwood Academic Publishers.

5. Woll, C. (1996). What difference does culture make? Providing treatment to women different from you. Journal of Chemical Dependency Treatment, 6, 67-85.

6. Gordon, J.U. (Ed.) (1994). Managing multiculturalism in substance abuse services. Thousand Oaks, CA: Sage Publications.

7. Cross, T. (2012). Cultural Competence Continuum. Journal of Child and Youth Care Work. National Organization of Child Care Worker Associations, Inc./0741-9481

8. Borrego, P., E. Ortiz-González and T. D. Gissandaner. (2019). Ethnic and Cultural Considerations, in Pediatric Anxiety Disorders. Academic Press. 461-497.

9. Olandi, M. (1992). Defining Cultural Competence: An organizing framework. In: M. Olandi (Ed) Cultural Competence for Evaluators: A guide for alcohol and other drug abuse prevention practitioners working with ethnic/racial communities. Rockville, MD: U.S. Department of HHS.

10. Davis, L. \& Proctor, E. (1989). Race, Gender, and Class: Guidelines for Practice. New Jersey: Prentice-Hall.

11. Cory, G. (2017). Theory and Practice of Counseling and Psychotherapy. New York: Cengage
Publishing.

12. Beutler, L.E., Zetzer, H., and Yost, E. (1997). Tailoring interventions to clients: Effects on engagement and retention. In L.S. Onken, J.D. Blaine, and J.J. Boren (Eds.), Beyond the therapeutic alliance: Keeping the drug-dependent individual in treatment. NIDA Research Monograph 165. Rockville, MD: U.S. Department of Health and Human Services. 85-109.

13. Barbujani G. (2005) Human races: Classifying people vs. understanding diversity. Current Genomics 6:215-226

14. Wang, V. Ota. (2001). Counseling and Psychotherapy: Ethnic and Cultural Differences. in International Encyclopedia of the Social \& Behavioral Sciences.

15. Brisbane, F. L., and Womble, M. (1992). Working with African Americans: The Professional Handbook, 1992. Chicago: HRDI International Press.

16. Anderson NB, Bulatao RA, Cohen B, (editors). (2004). Critical Perspectives on Racial and Ethnic Differences in Health. National Research Council (US). Race, Ethnicity, and Health in Later Life. Washington (DC): National Academies Press (US).

17. Yang, P. (2000). Theories of Ethnicity. In: Ethnic Studies Issues and Approaches. State University New York Press. pp.39-60.

18. Leong, F. T., and Kim, H. W. (1991). Going beyond cultural sensitivity on the road to multiculturalism: Using the intercultural sensitizer as a counselor training tool. Journal of Counseling and Development. 70, 112-118.

19. Gordon, J.U. (Ed.) (1994). Managing multiculturalism in substance abuse services. Thousand Oaks, CA: Sage Publications.

20. White et. Al. (2009) The Recovery Revolution: Will it include children, adolescents, and transition-age youth?

21. Mason, J.L., (1995). Cultural competence assessment questionnaire: A manual for users. Portland, OR: Portland State University Research and Training Center on Family Support and Children's Mental Health.

22. McLamore, S., and H. Romo. (1998). Racial and Ethnic Relations in America. Boston: Allyn and Bacon.

23. Jung, C.G. (1980). The Archetypes and the Collective Unconscious. Princeton, NJ: Princeton University Press.

24. Healthy People 2000 Progress Review. (1997). U.S. Department of Health and Human Services. Rockville, MD: Alcohol, Drug Abuse, and Mental Health Administration.

25. Frieden TR. (2010). A framework for public health action: the health impact pyramid. Am J Public 
Health. 2010;100(4):590-595.DOI:10.2105/ AJPH. 2009.185652.

26. Scoles, P, and F. DiRosa (2018). Social Determinants of Health and Behavioral Health Challenges. Counselor. Vol. 19. No.3. May/June.

27. Magnan, S., 2017. Social Determinants of Health 101 for Health Care: Five Plus Five. NAM Perspectives. Discussion Paper, National Academy of Medicine, Washington, DC. DOI: 10.31478/201710c

28. Michener, J., D. Koo, B. Castrucci, and J. Sprague, (Eds). Practical Playbook, Public Health, and Primary Care Together. (2016). Oxford University Press.

29. White W, Sanders M. (2008) Recovery management and people of color redesign addiction treatment for historically disempowered communities. Alcoholism Treatment Quarterly. Vol. 26(3):365395.

30. Scoles P. (2020) Spirituality, Culture, and the Process of Assessment in Recovery. Journal of Addictive Behaviors, Therapy \& Rehabilitation. Vol. 9:2.

31. Scoles, P. (2020). Building recovery resilience through culture, community, and spirituality. Journal of Behavioral Health. 9.(1): 275-281.

32. Scoles, P. (2020). Health and the healing process of recovery. Journal of Addiction and Recovery. Volume 3:1.

33. www.facesandvoicesofrecovery.org/blog/2016/0 $1 /$ new-recovery-movementbasics). 